\title{
Community of Inquiry: social presence revisited
}

\author{
KAREL KREIJNS \\ Scientific Centre for Teacher Research, Open University of the Netherlands \\ FREDERIK VAN ACKER \\ School of Psychology, Open University of the Netherlands \\ MARJAN VERMEULEN \\ KPC Groep, Teacher University, Open University of the Netherlands \\ HANS VAN BUUREN \\ School of Psychology, Open University of the Netherlands
}

\begin{abstract}
Social presence is a construct that has attracted the attention of many educational scholars involved in online collaborative learning settings wherein all the dialogue is happening through textbased asynchronous and synchronous communication channels. The social presence of the learning group members is associated with the degree of participation and social interaction amongst them and, as such, is therefore considered a critical variable for learning. The Community of Inquiry (CoI) framework defines social presence as the ability to project one's personal identity in the online community so that she or he is perceived as a 'real' person and/or as progressing through the phases (1) acquiring a social identity, (2) having purposeful communication, and (3) building relationships. However, the CoI social presence construct and its operationalization still leave many issues open. In this article, the original social presence construct is disentangled, concluding that it actually represents two constructs, namely (1) 'social presence' (degree of 'realness' of the other in the communication), and (2) 'social space' (degree to which social interpersonal relationships are salient). It is identified that social presence in the CoI model is actually integrating both constructs but with an emphasis on social space. Extending the CoI framework by making a distinction between social presence and social space is beneficial to the CoI model, because attention to its design and implementation can now be more precise. In addition, as social presence and social space are both progressive and developmental in nature, it fits the underlying philosophy of the CoI framework that embraces this dynamic characteristic.
\end{abstract}

\section{Introduction}

Social presence is a construct that has attracted the attention of many educational scholars involved in online collaborative learning settings wherein all the dialogues and conversations are mostly happening through text-based communication channels such as asynchronous discussion boards and synchronous chat-based systems. Social presence is associated with the degree of participation and social interaction amongst the collaborative group members and, as such, is therefore considered a critical variable for learning (Picciano, 2002; Koh et al, 2007; Yang et al, 2007; Goggins et al, 2009). Indeed, Tu (2000), linking social learning theory to social presence, asserts that social presence is required to enhance and foster online social interaction, which is the major vehicle of social learning' (p. 27). And, because social presence is so important for maintaining a high degree of online social interaction, it is a significant predictor of course retention and final grade in the community college online environment' (Liu et al, 2009, p. 165). Also, social presence is associated 
with learning outcomes and the degree of satisfaction of the group members (Gunawardena $\&$ Zittle, 1997; Garrison \& Arbaugh, 2007).

The Community of Inquiry (CoI) framework is a model that integrates social presence with two other kinds of presence, namely teaching presence and cognitive presence, in order to inform the practice of online (and blended) teaching and collaborative learning (Garrison et al, 2000, 2010). The CoI framework will be described in the next section. Since its inception almost 13 years ago considerable research has been conducted to assess its applicability and validation as a process model for understanding how deep and meaningful learning can be achieved (Garrison $\&$ Arbaugh, 2007; Arbaugh et al, 2008). The results so far have been promising, thus justifying further research on this topic as some issues remain unresolved or unclear. Precisely because of the latter, a critical debate has emerged in recent years starting with the original authors of the CoI framework who critically reflected upon some methodology issues that arose in their analysis of the transcripts, for instance, the issue of reliability when coding text elements (see Garrison \& Arbaugh, 2007; Garrison, 2008). A CoI survey instrument was therefore designed as an alternative to transcript analysis to assess the three kinds of presences (Arbaugh et al, 2008). Some scholars doubt whether the CoI framework can be used to elicit deep and meaningful learning that leads to positive learning outcomes (Rourke \& Kanuka, 2009; a response was given by Akyol et al, 2009) or that the role of social presence is overestimated in the CoI framework (Annand, 2011; a response to which was published by Garrison, 2011). Although these critical debates are still ongoing (see Xin, 2012), several other scholars have sought ways to strengthen the CoI framework by refining it instead of participating in this critique. For example, Shea and Bidjerano (2010, 2012) and Shea et al (2012) have extended the CoI framework to include learning presence as a fourth kind of presence.

In the same spirit we have looked for ways to strengthen the CoI social presence [1] construct because its conceptualization as well as its operationalization still leave many issues to be resolved (see Lowenthal, 2009, 2010). In order to resolve the issues surrounding the CoI social presence construct, we went back to the origins of social presence; that is, we started with the definition of social presence as was given by Short et al (1976) which is 'degree of salience of the other person in the interaction and the consequent salience of their interpersonal relationship' (p. 65). We did so because the various conceptualizations, definitions, and operationalizations of social presence that have come into existence seem to have been originally based on or inspired by their definition. In our belief, it is these divergences from the original definition that have led to the current confounding situation. Indeed, Lowenthal (2010) points out that 'despite its intuitive appeal, researchers and practitioners alike often define and conceptualize this popular construct differently. In fact, it is often hard to distinguish between whether someone is talking about social interaction, immediacy, intimacy, emotion, and/or connectedness when they talk about social presence' (p. 125). In our view, the situation is confounded by four issues: the first is that social presence as 'salience of the other' (i.e. the degree of 'realness' of the other in the communication) is made equal with 'salience of the interpersonal relationship' rather than viewing the latter as a consequence, as was stated by Short et al (1976). With 'realness' (or 'real') we mean that although we know that the other is not physically present in the communication, we nevertheless experience the feeling that this is - to some degree - so. In our view, which will be elaborated in depth in a later section, we consider social presence to be associated with salience of the other. As a consequence, we have labelled salience of the interpersonal relationship(s) rather as social space. A sound social space is manifest if, among other things, group members trust each other and if group cohesion, a sense of community, and an open atmosphere exist amongst the members.

The second issue involves a discussion about technological determinism versus sociological determinism. It has its basis in the question of whether social presence is determined by the technological attributes of the communication media or is determined by the social group using those media. Gunawardena (1995) and Gunawardena and Zittle (1997) have found that it is not media characteristics as such but rather the students' perceptions of communicating through a textbased media that correlates with social presence. Nevertheless, presence researchers suggest that media characteristics do contribute to the perception of social presence (Biocca et al, 2003; de Ruyter et al, 2006; Horvath \& Lombard, 2009). As a result, we see social presence as co-determined on the one hand by the physical characteristics of the communication medium and on the other hand by a contingency of social influence factors such as social context, social processes, and so forth. In addition, teacher factors, such as the pedagogical techniques they use and how they 
cultivate social presence amongst the group members, play a role as well. In terms of the CoI framework, this last factor would be the teaching presence.

The third issue is that definitions of social presence do not always refer to 'salience of the other' (i.e. referring to a person's perception) but more often refer to the ability to project oneself (i.e. referring to a person's ability). This is the case with the CoI social presence conceptualization (see Garrison et al, 2000). In our view, social presence is a perceptual phenomenon rather than an ability.

Finally, the fourth issue arises from the fact that social presence is not always operationalized in a manner congruent with its definition. For example, although Rourke and Anderson (2002) defined social presence as 'salience of the other,' they nevertheless assessed social presence by measuring social climate. In our view, any instrument that assesses social presence as salience of the other should focus on the measurement of how group members perceive 'realness' of the other.

In this article, we clarify the social presence construct and show that it may actually represent two constructs, namely (1) 'social presence' (i.e. the degree of 'realness' of the other in the communication), and (2) 'social space' (i.e. the degree to which social interpersonal relationships are salient). We further identify that social presence in the CoI model actually represents both constructs, but that it gives emphasis to social space. Accordingly, the CoI survey instrument (Arbaugh et al, 2008) reflects this fact. The article starts with a description of the general CoI framework; it further explains how social presence as defined in this framework is conceptualized and how it is operationalized. It continues with a discussion of the Short et al (1976) conceptualization of social presence and shows that CoI social presence can actually be disentangled into two separate, but related constructs, namely 'social presence' and 'social space'. It then describes the two constructs and how they extend the CoI framework. Finally, future research is discussed.

\section{The CoI Framework}

The Community of Inquiry (CoI) framework proposed by Garrison et al $(2000,2010)$ argues that a complete educational experience in an online collaborative learning setting will develop only if three kinds of presence exist in such a community: cognitive presence, social presence, and teaching presence. Cognitive presence is defined as the extent to which learners are able to construct and confirm meaning through sustained reflection and discourse' (Garrison et al, 2001, p. 11). Cognitive presence, thus, reflects higher order knowledge construction through critical thinking and is 'intimately connected to the learning context' (Garrison \& Anderson, 2003, p. 29). Social presence is defined as the ability to project one's personal identity in the online community so that one is perceived as a 'real' person (Garrison et al, 2000). Garrison et al (2000), argue that social presence is important because it functions as 'a support for cognitive presence, indirectly facilitating the process of critical thinking carried on by the community of learners ... and is a direct contributor to the success of the educational experience' (p. 89). Therefore, Garrison and Anderson (2003) suggest that 'cognitive presence is enhanced and sustained when social presence is established' (p. 29). Teaching presence is defined as 'the design, facilitation, and direction of cognitive and social processes for the purpose of realising personally meaningful and educationally worthwhile learning outcomes' (Anderson et al, 2001, p. 5). According to Garrison and Anderson (2003), teaching presence brings the two other types of presence together in a balanced and functional relationship, which is congruent with the intended outcomes and which takes the learners' needs and capabilities into account. In a certain way, a number of scholars anticipated the development of the teaching presence construct. For example, Gunawardena (1995) suggested a number of issues that must be addressed to support academic objectives in computer conferences. Among them are protocols for computer-mediated communication (CMC) interaction, procedures for signing on and using the system, etiquette for CMC discussion, and techniques for managing information overload. Additionally, she notes that 'conference moderators should facilitate discussions by recognising all contributions initially, summarising frequently, and weaving ideas together' (p. 163). Studies that explore the causal relationships between the different types of presence in the CoI have thus far found that social presence appears to be a mediator between 
teaching and cognitive presence and that teaching presence causally influences social and cognitive presence (Shea \& Bidjerano, 2009; Garrison et al, 2010).

\section{Social Presence within the CoI Framework}

Initially, the conceptualization of social presence within the CoI framework seems to have been inspired on Gunawardena's (1995) conception of social presence who, in turn, was inspired by Short et al (1976) as the originators of social presence theory. They used social presence theory to explain interpersonal effects between two interlocutors in an organisational setting when using four different types of communication media, namely audio channels, closed-circuit video channels, telephone, and face-to-face meetings. Short et al (1976) characterised each communication medium in terms of its potential to communicate non-verbal and verbal cues conveying socio-emotional information so that the other is perceived as physically 'real'. Nonverbal cues are expressed by vision (e.g. facial expression, direction of gaze, posture, gestures, eyecontact), audition (e.g. voice volume, inflection, soft speaking), tactile (e.g. touching, shaking hands), and olfaction (e.g. smells, body odours). Gunawardena (1995) and Gunawardena and Zittle (1997) applied social presence theory in an educational setting to understand learning in online conferencing groups and many others have followed since then (amongst them are: Tu, 2000; Rourke \& Anderson, 2002; Shin, 2002; Stacey, 2002; Swan, 2002; Tu \& McIsaac, 2002; Richardson, \& Swan, 2003; Shen et al, 2006; Koh et al, 2007; Yang et al, 2007; Kehrwald, 2008; Goggins et al, 2009; Lowenthal, 2009, 2010; Kear, 2010). As mentioned before, social presence is important because it affects participation and social interaction, which are necessary for effective collaboration and knowledge construction. However, it was suggested that particularly in online collaborative learning environments using text-based asynchronous communication media (e.g. discussion boards), it would be difficult to establish social presence because these environments cannot transfer the non-verbal cues that are needed in the process of becoming a 'real' person for the other. However, Gunawardena (1995) contended that social presence can be cultured if participants have the ability to project their identities through carefully drafted messages. This will help them to build online communities, she reasoned, because these messages help them to be perceived as 'real'. Garrison (1997) considered the ability to achieve this as social presence and defined it as 'the degree to which participants are able to project themselves affectively within the medium' (p. 6). Garrison et al (2000) reformulated this definition for their CoI framework as the 'ability of participants in a community of inquiry to project themselves socially and emotionally, as 'real' people (i.e. their full personality), through the medium of communication used' (p. 94). In other words, they maintain that the competency to develop social presence is social presence.

Recently, Garrison (2009) saw social presence as progressing through the phases: (1) acquiring a social identity, (2) have purposeful communication, and (3) building relationships. Accordingly, he defined social presence as 'the ability of participants to identify with the community (e.g. course or study), communicate purposefully in a trusting environment, and develop interpersonal relationships by way of projecting their individual personalities' (p. 352). Garrison has done so to streamline the conceptualization of social presence with the conceptualizations of the other presences - particularly with regard to their progressive and developmental nature. According to Garrison et al (2010) ' $[\mathrm{i}] \mathrm{t}$ is this progressive nature of the presences that was never quite made explicit in the original conceptualization' (p. 7).

\section{The Measurement of Social Presence}

Content analysis has been the primary methodology to assess the degree of social presence (Rourke et al, 1999). Three categories of behaviour were defined that operationalized social presence: group cohesion (reflecting the shared social identity of the community and its collaborative behavioural intention), open communication (reflecting the interactive and purposeful nature of the communication), and affective expression (reflecting the socio-emotional components of the communication for the purpose of forming interpersonal relationships). Indicators for group cohesion are vocatives (i.e. addressing participants by name), using inclusive pronouns (i.e. addressing the group as we, us, our group), and phatics or salutations (e.g. greetings, closures); 
indicators for open communications are continuing a thread, quoting from others' messages, referring explicitly to others' messages, asking questions and getting feedback, complimenting or expressing appreciation, and expressing agreement. Finally, indicators of affective expression include expressions of emotions (e.g. use of emoticons, conspicuous capitalization), use of humour (e.g. irony, teasing, cajoling, sarcasm), and self-disclosure (e.g. presenting details of personal life, expressing vulnerability). As Garrison (2009) elaborated, the categories of this operationalization of social presence can be seen as phases of a process in which first a shared social identity - derived from the purpose of the course - is the primary concern, and then later, is the basis for the formation of interpersonal relationships. This viewpoint has led to the more recent definition of social presence as is outlined above.

Recently, a CoI survey instrument that assesses the student's perception about the manifestation of each of the presences was developed and validated (Arbaugh et al, 2008). Díaz et al (2010), and Carlon et al (2012) also validated the instrument using different settings, hence, the CoI survey instrument seems to enable a quantitative approach to the study of the dynamic relationships between cognitive, social, and teaching presence without using laborious transcript analyses. Table I depicts the social presence scale of the CoI survey instrument which consists of nine items (items 14-22). Items 15, 16, 17, 18, 19, and 21 directly correspond to items of the Social Presence Scale of Gunawardena and Zittle (1997). Table I first shows the items according to their social presence categories (i.e. group cohesion, open communication and affective expression); however, these categories have only been derived theoretically, but never empirically verified. Indeed, Carlon et al (2012) performed an empirical study and found a two-factor rather than a three-factor structure for social presence. They designated the two factors (i.e. categories) as social comfort and social experience. From our perspective, these results suggest that the factor of social comfort is actually yet another construct that represents the overall friendliness of online collaborative learning and, thus, is not a real dimension of social presence. Its items, namely, seem to emphasize feelings of comfort about the interaction (i.e. conversing, participating, interacting, disagreeing, acknowledging) and not so much the interaction itself in a specific configuration/setting. Table I also shows how the social presence items as defined in the CoI are categorized in the empirically derived categories of social comfort and social experience.

\begin{tabular}{|c|c|c|c|c|c|c|c|c|c|c|c|}
\hline $\begin{array}{l}\text { Item } \\
\text { no. }\end{array}$ & Item & \multicolumn{3}{|c|}{$\begin{array}{l}\text { Theoretically derived categories } \\
\text { (see appendix A of Díaz et al, } \\
\text { 2010) }\end{array}$} & \multicolumn{2}{|c|}{$\begin{array}{l}\text { Empirically derived } \\
\text { categories } \\
\text { (Carlon et al, 2012) }\end{array}$} & \multicolumn{4}{|c|}{$\begin{array}{l}\text { Hypothesized categories } \\
\text { (this article) }\end{array}$} & $\begin{array}{l}\text { Item no. off the } \\
\text { Social Presence } \\
\text { Scale } \\
\text { (Gunawardena } \\
\text { \& Zittle, 1997) }\end{array}$ \\
\hline 14 & $\begin{array}{l}\text { Getting to know other course } \\
\text { participants gave me a sense of } \\
\text { belonging in the course }\end{array}$ & & & $\sqrt{ }$ & & $\sqrt{ }$ & & $\sqrt{ }$ & & & \\
\hline 16 & $\begin{array}{l}\text { Online or web-based } \\
\text { communication is an excellent } \\
\text { medium for social interaction }\end{array}$ & & & $\sqrt{ }$ & & $\sqrt{ }$ & & & $\sqrt{ }$ & & 2 \\
\hline 17 & $\begin{array}{l}\text { I felt comfortable conversing } \\
\text { through the online medium }\end{array}$ & & $\sqrt{ }$ & & $\sqrt{ }$ & & & & & $\sqrt{ }$ & 3 \\
\hline 21 & $\begin{array}{l}\text { I felt that my point of view was } \\
\text { acknowledged by other course } \\
\text { participants }\end{array}$ & $\sqrt{ }$ & & & $\sqrt{ }$ & & & $\sqrt{ }$ & & & 13 \\
\hline 22 & $\begin{array}{l}\text { Online discussions help me to } \\
\text { develop a sense of collaboration }\end{array}$ & $\sqrt{ }$ & & & & $\sqrt{ }$ & & $\sqrt{ }$ & & & \\
\hline
\end{tabular}

Judgments use 5-point Likert scale. Note: Response scales: $0=$ strongly disagree to $4=$ strongly agree.

Items 1-13, not shown here, represent teaching presence; items 23-34, also not shown here, represent cognitive presence.

Table I. The social presence scale of the CoI survey instrument. 
Finally and as was already mentioned before, we consider social presence to be associated with salience of the other and social space with salience of the interpersonal relationships. Hence, we have defined a social presence and social space category in order to categorize the CoI social presence items. We further added two more categories, attitude and social comfort, in order to categorize items that could neither be categorized as social presence nor as social space. We adopted the term 'social comfort' from Carlon et al (2012). However, in contrast to their use of the instrument, we did not categorize items 20 and 21 in the social comfort category but in the social space category. We did this because the two items refer to the soundness of the social space in which, amongst other things, mutual trust, sense of cohesion, and an open atmosphere exist. In that respect, our social space category is more similar to Diaz et al's (2010) social cohesion category. Also, our social comfort category is identical to their open communication category. Finally, following Fishbein and Ajzen (2010), item 16 is representative of the attitude towards online communication. Our four hypothesised categories are found in Table I and show how the CoI social presence items are categorized. As can be observed in Table I, only one item (item 15) represents social presence and four items (items 14, 20, 21, and 22) represent social space.

\section{CoI Social Presence Revisited}

As we have made clear in the previous sections, the CoI social presence construct and its operationalization still leave many issues open. In order to clarify things regarding CoI social presence, we went back to Short et al (1976) who were the first to define social presence. To repeat, they defined social presence as the 'degree of salience of the other person in the interaction and the consequent salience of the interpersonal relationship' (p. 65). Their definition can be broken up into two parts, the first part is the 'salience of the other person in the interaction' and the second part the consequence of this salience of the other - is, 'salience of the interpersonal relationship.' These two parts of Short et al's definition were also recognised by Vanden Abeele et al (2007) and by Kehrwald (2008), although they assigned different meanings to the first part. Vanden Abeele et al (2007) interpreted the first part as the situation in which the others are perceived as 'real' people. They feel that:
depending on the research domain, the focus is more on one rather than both of these two [parts]. While social presence, understood as 'the consequent salience of the interpersonal relationships', refers more to the domain of Interpersonal Communication, social presence, understood as 'the salience of another person in an interaction', refers more to the domain of Presence research. (p. 215)

Kehrwald (2008), in contrast, interprets the first part as emphasizing media characteristics, thus in correspondence with the technological perspective of Short et al (1976) who saw media attributes as influencing the degree of social presence, that is, they stated that social presence 'varies between different media, it affects the nature of the interaction and it interacts with the purpose of the interaction to influence the medium chosen by the individual who wishes to communicate' (p.65).

\section{Social Presence as Salience of the Other Person in the Interaction}

As argued before, we believe social presence is associated with the first part of the definition by Short et al (1976); in other words, we see social presence as salience of the other person in the interaction. We use the definition of Kreijns et al (2011) for social presence which is the 'degree of illusion that others appear to be a 'real' physical person in either an immediate (i.e. real time/synchronous) or a delayed (i.e. time-deferred/asynchronous) communication episode' (p. 366). Thus, social presence has to do with the degree of 'realness' of the other person in the communication. The definition is in line with what presence researchers have designated as social presence, namely 'the perceptual illusion of non-mediation [of the other]' (Lombard \& Ditton, 1997; Biocca et al, 2003). Furthermore, we do not adhere to a pure technological perspective but see social presence as co-determined by the physical characteristics of the communication media and by a contingency of social influence factors. This means that even if lean communication media are used (e.g. text-based asynchronous discussion boards) it is still possible to achieve a high degree of social presence through these media (Walther, 1992, 1993). Finally, we consider social 
presence as salience of the other as a necessary condition for establishing an interpersonal relationship between two interlocutors or, when it is already there, for sustaining such a relationship. Indeed, if one is not aware of the other because he or she is not in some way 'real,' it becomes very difficult to establish or sustain an interpersonal relationship.

Social presence may not instantly exist when using a lean communication medium. However, the online collaborative learning environment that CoI groups use is commonly equipped with such lean communication media. Therefore, it often takes time to develop social presence. The development of social presence runs alongside the development of social space and is centred around impression formation. Impression formation is a social cognitive process in which one develops individuating impressions of the others, in other words, where group members 'get to know each other' (Walther, 1993). Walther's (1992) social information processing (SIP) theory of mediated communication suggests that impression formation is facilitated through the accumulation of the messages transferred; these messages are generated during the episodes when group members have social interaction. One moment these messages may convey information about the members' personal lives (self-disclosure) and at another they may convey information about the interests they have, the knowledge and expertise they possess, what they find difficult or easy, or other types of relevant information. All these messages help to develop individuating impressions. SIP also suggests that members will 'acclimate to the restrictions of the media by adapting their language behaviour to fulfil the functions of missing nonverbal cues in such ways as to build interpersonal impressions, build mental models of their colleagues, and develop relationships marked by affective exchange' (Danchak et al, 2001, p. 2).

If the online collaborative learning environment features personal profile pages, group members may learn from these pages about the co-members and build individuating impressions even before they have ever communicated with them. Personal profile pages in an online collaborative learning environment are a technological feature that extends the functionality of the environment. This means that they are not an attribute of the communication medium as such but rather of the online collaborative learning environment. A number of researchers have tested the influence of many other features in an online collaborative learning environment; most notably are the group awareness tools, which make group members aware of the activities of the co-members, thereby potentially adding to impression formation. Because of space limitations, we cannot look in depth at group awareness tools, but further reading is available (e.g. Bodemer \& Dehler, 2011, who were the editors of a special issue about group awareness in computer-supported collaborative learning (CLCL) environments). Once individuating impressions or mental models of the other are formed, social presence will be present when group members are involved in social interaction.

\section{Social Space as Salience of the Interpersonal Relationships}

The second part of the definition of Short et al (1976) points to the interpersonal relationship between two interlocutors. In contrast, the CoI framework considers collaborative groups with possibly more than two members. Therefore, the second part is augmented to include all the interpersonal relationships that exist in a collaborating group instead of considering only one relationship. Kreijns et al (2004) have designated salience of interpersonal relationships as social space. They defined social space as 'the network of social relationships amongst the group members embedded in group structures of norms and values, rules and roles, beliefs and ideals' (p. 608). They consider the set of interpersonal relationships as a network because each member may have a social relationship with the other members so that each member is 'connected' with the other members. Upon observing all of these connections, one can see that they form a kind of social network. Of course, when dealing with small groups, consisting of two to four or five members such as CoI groups, it is perhaps uncommon to actually designate these as a social network; however, in large groups with over a hundred or even a thousand members such a designation can certainly apply. Such a large group is found, for example, in the social network site Facebook (see Cheung et al, 2011). Therefore, the social space definition is applicable to both small and large groups. Social space is sound when it provides features encompassing, among others and depending on the context, affective work relationships, shared social identity, group cohesiveness, 
mutual trust, a sense of belonging, a sense of community, and an open atmosphere. Indeed, according to Cherrington (1989, as cited by Management Class, 2014):

\begin{abstract}
effective groups have several characteristics: the atmosphere is close and friendly; all members participate in the group; all members are committed to the group's goals; members listen to each other and share information; decisions are made by consensus; conflict is dealt with openly and resolved; members receive frank and objective feedback and feel free to express their feelings openly; there is a division of labour with shared leadership; and the group is aware of its own operations and able to monitor itself. ( $§$ Characteristics of effective groups)
\end{abstract}

These features are essentially the same features that characterise CoI social presence (see Table I). Therefore, we believe social space to be similar to CoI social presence.

\title{
The Emergence of Social Space
}

The extent to which a social space develops in a group depends largely on how the interpersonal and social relationships develop. These interpersonal relationships emerge through socioemotional processes involving affiliation, attraction and impression formation. Affiliation is the propensity people have to get in contact with others. A reason for affiliation within a CoI group is that members perceive that they are mutually dependent on each other for successfully accomplishing the working and learning tasks. Also, each group member will develop individuating impressions of the co-members. Based upon these impressions, they can develop (initial) relationships with other members. The kind of social relationship is, amongst other things, determined by the attractiveness of the co-member. Attractiveness is the feeling that a group member has about the other group members, which is influenced by affection, status, and competence (e.g. leadership).

All of these processes start at the moment a CoI group is formed. According to Tuckman (1965) the forming of a group is the first of the four phases of the lifecycle of a group; it is the phase of 'getting to know one another', in which each member is oriented to the learning tasks they have to perform, as well as the roles and leadership. The other successive phases are storming, norming, and performing. Tuckman and Jensen (1977) added a fifth phase, namely adjourning, when the group splits apart. The storming phase is the phase of disagreement and conflict. Group members may vie for leadership and the roles they have to perform. Also, a debate may start about the rules in the group: how should members behave and what is expected from them? If consensus through resolution is achieved, the group moves into the norming phase. In this phase, the group structures become clear, that is, the group norms and values are clearly communicated and each member knows what role he or she is expected to perform. In addition, expectations in terms of beliefs and ideas are established. It is the phase in which social relationships become stable and feelings of group cohesiveness begin to develop as well as a social identity. When looking at the Garrison et al (2010) CoI social presence definition as a three-phase process, acquiring a social identity is accomplished in this norming phase. The next phase - the performing phase - is the most important phase because in this phase the group has matured and all group members are focused on the group learning tasks and collaborating to achieve the group goals. It is the phase in which the social space is sound: there is group cohesiveness, a feeling of belonging, an open atmosphere and mutual trust. In terms of CoI social presence definition as a three-phase process, group members have purposeful communication. After the task is accomplished, group members go their own way; this phase is the adjourning phase. Tuckman (1965) and Tuckman and Jensen (1977) saw all five phases as consecutive phases; however, reality showed that not all groups progress in a linear fashion through these phases. Therefore, Bales (1965) introduced a cyclic version, in which the group may cycle through the phases storming, norming, and performing. The latest insights suggest that it is always possible to step back one phase or even start all over again in the storming phase. Thus, if a group has reached the performing phase, it may fall back either into the norming phase or the storming phase, depending on whatever caused the fallback. For example, if a group starts to believe that the task will not be ready at the time of the deadline, a worried group may call for new leadership. In addition, if members in the storming phase cannot reach consensus, this could imply that the group will be disbanded, and thus the group will enter into the adjourning phase. 
Figure 1 depicts the correspondences between the different conceptualizations of the social presence construct discussed in this section.

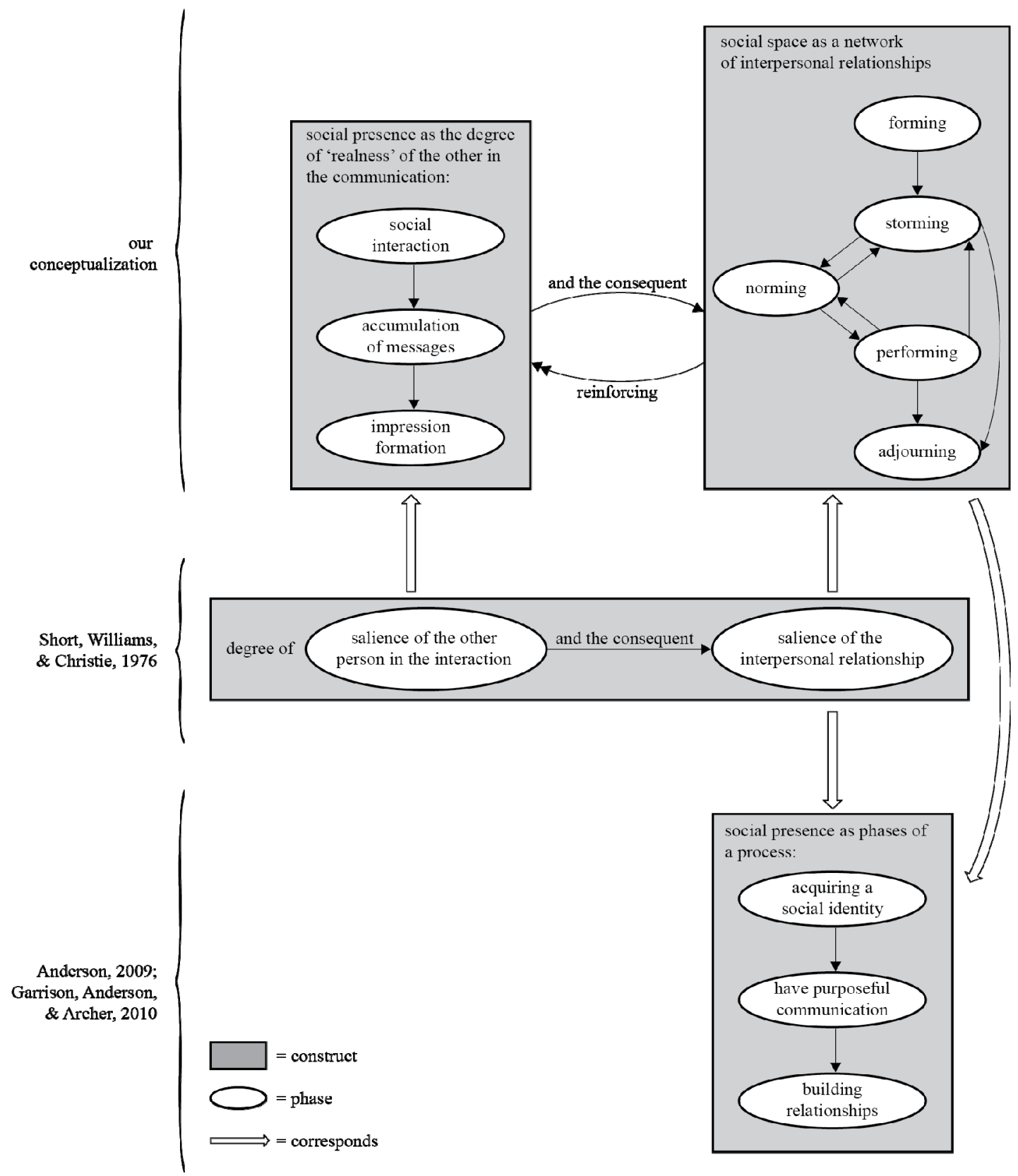

Figure 1. Correspondences between the different conceptualizations of the social presence construct.

\section{Extending the CoI framework}

Figure 2 depicts the extended CoI framework which now includes our conceptualizations of social presence and social space. As can be observed in this figure, we have also incorporated learning presence as proposed by Shea and Bidjerano $(2010,2012)$ as well as educational resources. With respect to the learning presence, Shea and Bidjerano (2012) refer to a study of Allen and Seaman (2010) in which it was concluded that 'a majority of institutions in the US reported that online learning requires more discipline on the part of the student and that this represents a barrier to continued growth of online education' (p. 317). Therefore, Shea and Bidjerano (2010, 2012) place their attention on issues of self-regulation such as online student discipline, self-directedness, and 
self-reliance. They labelled the online learner's self-regulation as learning presence and stated that this is an important component to consider within the CoI framework as their studies provided evidence that it has relationships with cognitive, social, and teaching presence and, as a consequence, on learning outcomes. Because of their findings, we have incorporated learning presence in the extended CoI framework. Educational resources refer to all the resources a teacher may use in order to exert teaching presence. Our interest in educational resources has grown since the availability of (open) educational resources that allow teachers to build their own curricula, their own lesson plans, and to integrate information and communication technologies (ICTs) in their pedagogical practices. This potential from (open) educational resources and ICTs may enable, support, and reinforce educational reform that stresses a learner-centred approach rather than a teacher-centred approach (Ward, 2005). A learner-centred approach emphasizes active learning, critical thinking, collaborative inquiry, problem-solving skills, communication skills, information handling skills, self-directed learning, and connectedness with others, all of which are necessary for stimulating the development of life-long learning competencies (Hargreaves, 2003). These characteristics are usually referred to as 'twenty-first century skills' because they are considered necessary to meet the educational demands of the twenty-first century imposed by the knowledge society (Somekh, 2007). These considerations motivated us to incorporate educational resources within the CoI framework.

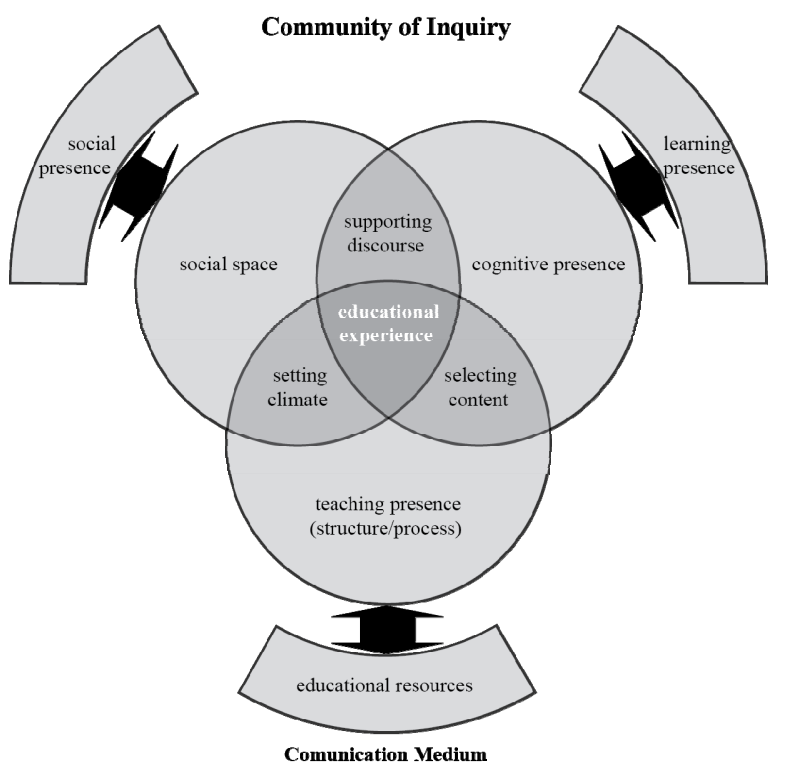

Figure 2. The extended Community of Inquiry framework.

\section{Concluding Remarks and Future Research}

In this article we have examined our latest ideas regarding the social presence construct and have studied how it was generally conceptualized and operationalized, in particular within the context of the CoI framework. We agree with Lowenthal (2010) that the conceptualization and operationalization of social presence is confounding and that many issues are left open. In particular, we found this true for the CoI social presence construct. Therefore, we went back to the origins of social presence as was formulated by Short et al (1976). It turned out that their definition actually represents two constructs, namely (1) 'social presence' (as the degree of 'realness' of the other in the communication), and (2) social space (as the degree to which social interpersonal relationships are salient). We further identified that social space has conceptually a lot in common with CoI social presence. We extended the CoI framework by replacing CoI social presence with our conceptualization of social presence and social space. We also incorporated learning presence and educational resources (see Figure 3). Such an extension of the CoI framework is beneficial because further attention to its design and implementation can now be more focused. In addition, 
as social presence and social space are both progressive and developmental in nature, it fits the underlying philosophy of the CoI framework that embraces this dynamic characteristic.

Our future research will orient towards the operationalization of social presence and social space. That is, existing instruments will be reviewed including those developed by Kreijns et al (2004, 2011), the CoI survey instrument (Arbaugh et al. 2008) as well as others (e.g. Gunawardena \& Zittle, 1997; Tu, 2002; Vanden Abeele et al, 2007;). In particular, with respect to the operationalization of social presence, we tend to agree with Vanden Abeele et al's (2007) suggestion that the extent to which social presence exists in a virtual environment can be inferred from Zajonc's social facilitation theory. 'If the social facilitation framework can be successfully applied, this would provide us with extra evidence that perceptual presence is a prerequisite property of social presence' (1965, p. 217). Zajonc's (1965) social facilitation theory states that people will tend to do better when performing simple familiar tasks and tend to do worse when performing difficult unfamiliar tasks when they become aware of the mere or imagined presence of other people. They found support for the mere presence effect though the evidence was somewhat limited. Inspired by social facilitation theory and the findings of Vanden Abeele et al (2007), we expect that the way members of a CoI behave online is indicative of how they experience the degree of physical 'realness' of the other members. More precisely, it is expected that communication style, language style, and responsiveness will be more similar amongst the members when social presence is high.

We hope that the extended CoI framework will advance our knowledge about the CoI framework and that quantitative research on it is stimulated as soon as the operationalizations of the social presence and social space instruments become available.

\section{Note}

[1] We refer to the CoI conceptualization of social presence as 'CoI social presence' rather than 'social presence' unless it is unambiguously clear that we mean the CoI conceptualization of it.

\section{References}

Akyol, Z., Arbaugh, B., Cleveland-Innes, M., et al (2009) A Response to the Review of the Community of Inquiry Framework, Journal of Distance Education, 23(2), 123-136.

Allen, E. \& Seaman, J. (2010) Class Differences: online education in the United States. Needham, MA: Sloan Consortium.

Anderson, T., Rourke, L., Garrison, D.R. \& Archer, W. (2001) Assessing Teaching Presence in a Computer Conferencing Context, Journal of Asynchronous Learning Networks, 5(2), 1-17.

Annand, D. (2011) Social Presence within the Community of Inquiry Framework, International Review of Research in Open and Distance Learning, 12(5), 38-54.

Arbaugh, J.B., Cleveland-Ines, M., Diaz, S., et al (2008) Developing a Community of Inquiry Instrument: testing a measure of the community of inquiry framework using a multi-institutional sample, The Internet and Higher Education, 11(3-4), 133-136. http: / / dx.doi.org/10.1016/j.iheduc.2008.06.003

Bales, R.F. (1965) The Equilibrium Problem in Small Groups, in A.P. Hare, E.F. Borgatta \& R.F. Bales (Eds) Small Groups: studies in social interaction. New York: Knopf.

Biocca, F., Harms, C. \& Burgoon, J.K. (2003) Toward a More Robust Theory and Measure of Social Presence: review and suggested criteria, Presence: Teleoperators and Virtual Environments, 12(5), 456-480. http: / / dx.doi.org/10.1162/105474603322761270

Bodemer, D. \& Dehler, J. (2011) Group Awareness in CSCL Environments, Computers in Human Behavior, 27(3), 1043-1045. http:/ / dx.doi.org/10.1016/j.chb.2010.07.014

Carlon, S., Bennett-Woods, D., Berg, B., et al (2012) The Community of Inquiry Instrument: validation and results in online health care disciplines, Computers \& Education, 59(2), 215-221. http: / / dx.doi.org/10.1016/j.compedu.2012.01.004

Cherrington, D.J. (1989) Organisational Behaviour. Boston, MA: Allyn \& Bacon.

Cheung, C.M.K., Chiu, P-Y. \& Lee, M.K.O. (2011) Online Social Networks: why do students use Facebook?, Computers in Human Behavior, 27(4), 1337-1343. http: / / dx.doi.org/10.1016/j.chb.2010.07.028 
Danchak, M.M., Walther, J.B. \& Swan, K.P. (2001) Presence in Mediated Instruction: bandwidth, behavior, and expectancy violations. Paper presented at the 2001 ALN conference. Orlando, FL, 17-19 November.

De Ruyter, B., Huijnen, C., Markopoulos, P. \& IJsselsteijn, W.A. (2006) Creating Social Presence through Peripheral Awareness, in E. Aarts \& E. Diederiks (Eds) Ambient Lifestyle: from concept to experience, pp. 69-71. Amsterdam: BIS Publishers.

Diaz, R., Swan, K., Ice. P. \& Kupczynksi, L. (2010) Student Ratings of the Importance of Survey Items, Multiplicative Factor Analysis, and the Validity of the Community of Inquiry Survey, The Internet and Higher Education, 13(1-2), 22-30. http:/ / dx.doi.org/10.1016/j.iheduc.2009.11.004

Fishbein, M. \& Ajzen, I. (2010) Predicting and Changing Behavior: the reasoned action approach. New York: Psychological Press.

Garrison, D.R. (1997) Computer Conferencing: the post-industrial age of distance education, Open Learning, 12(2), 3-11. http: / / dx.doi.org/10.1080/0268051970120202

Garrison, D.R. (2008) Online Community of Inquiry Review: social, cognitive, and teaching presence issues, Journal of Asynchronous Learning Networks, 11(1), 61-72.

Garrison, D.R. (2009) Communities of Inquiry in Online Learning, in P.L. Rogers (Ed.) Encyclopedia of Distance Learning, 2nd edn, pp. 352-355. Hershey, PA: IGI Global.

Garrison, D.R. (2011) Article Review - Social Presence within the Community of Inquiry Framework, International Review of Research in Open and Distance Learning, 13(1), 250-252.

Garrison, D.R. \& Anderson, T. (2003) E-Learning in the 21st Century: a framework for research and practice. London: RoutledgeFalmer. http:/ / dx.doi.org/10.4324/9780203166093

Garrison, D.R., Anderson, T. \& Archer, W. (2000) Critical Thinking in a Text-based Environment: computer conferencing in higher education, The Internet and Higher Education, 2(2), 87-105.

Garrison, D.R., Anderson, T. \& Archer, W. (2001) Critical Thinking, Cognitive Presence, and Computer Conferencing in Distance Education, American Journal of Distance Education, 15(1), 7-23. http: / / dx.doi.org/10.1080/08923640109527071

Garrison, D.R., Anderson, T. \& Archer, W. (2010) The First Decade of the Community of Inquiry Framework: a retrospective, The Internet and Higher Education, 13(1-2), 5-9. http:/ / dx.doi.org/10.1016/j.iheduc.2009.10.003

Garrison D.R. \& Arbaugh, J.B. (2007) Researching the Community of Inquiry Framework: review, issues, and future directions, The Internet and Higher Education, 10(3), 157-172. http: / / dx.doi.org/10.1016/j.iheduc.2007.04.001

Garrison, D.R., Cleveland-Innes, M. \& Fung, T.C. (2010) Exploring Causal Relationships among Teaching, Cognitive and Social Presence: student perceptions of the community of inquiry framework, The Internet and Higher Education, 13(1-2), 31-36. http: / / dx.doi.org/10.1016/j.iheduc.2009.10.002

Goggins, S.P., Laffey, J. \& Galyen, K. (2009) Social Ability in Online Groups: representing the quality of interactions in social computing environments, in Proceedings of the 12th IEEE International Conference on Computational Science and Engineering, 29-31 August, vol. 4, pp. 667-674. Vancouver, BC, Canada: IEEE Computer Society.

Gunawardena, C.N. (1995) Social Presence Theory and Implications for Interaction and Collaborative Learning in Computer Conferences, International Journal of Educational Telecommunications, 1(2-3), 147-166.

Gunawardena, C.N. \& Zittle, F. (1997) Social Presence as a Predictor of Satisfaction within a Computer Mediated Conferencing Environment, American Journal of Distance Education, 11(3), 8-25. http: / / dx.doi.org/10.1080/08923649709526970

Hargreaves, A. (2003) Teaching in the Knowledge Society: education in the age of uncertainty. Maidenhead: Open University Press.

Horvath. K. \& Lombard, M. (2009) Social and Spatial Presence: an application to optimize human-computer interaction. Paper presented at the 12th annual international workshop on presence, 11-13 November, Los Angeles, CA.

Kear, K. (2010) Social Presence in Online Learning Communities, in L. Dirckinck-Holmfeld, V. Hodgson, C. Jones, et al (Eds) Proceedings of the 7th International Conference on Networked Learning 2010, 3-4 May, Aalborg, Denmark.

Kehrwald, B. (2008) Understanding Social Presence in Text-based Online Learning Environments, Distance Education, 29(1), 89-106. http:/ / dx.doi.org/10.1080/01587910802004860

Koh, J., Kim, Y.-G., Butler, B. \& Bock, G.-W. (2007) Encouraging Participation in Virtual Communities, Communications of the ACM, 50(2), 69-73. http: / dx.doi.org/10.1145/1216016.1216023 
Kreijns, K., Kirschner, P.A., Jochems, W. \& Van Buuren, H. (2004) Measuring Perceived Quality of Social Space in Distributed Learning Groups, Computers in Human Behavior, 20(5), 607-632. http: / / dx.doi.org/10.1016/j.chb.2003.11.002

Kreijns, K., Kirschner, P.A., Jochems, W. \& Van Buuren, H. (2011) Measuring Perceived Social Presence in Distributed Learning Groups, Education and Information Technologies, 16(4), 365-381. http: / / dx.doi.org/10.1007/s10639-010-9135-7

Liu, S.Y., Gomez, J. \& Yen, C.-J. (2009) Community College Online Course Retention and Final Grade: predictability of social presence, Journal of Interactive Online Learning, 8(2), 165-182.

Lombard, M. \& Ditton, T. (1997) At the Heart of it All: the concept of presence, Journal of Computer-Mediated Communication, 3(2). http:/ / jcmc.indiana.edu/vol3/issue2/lombard.html

Lowenthal, P.R. (2009) Social Presence, in P. Rogers, G. Berg, J. Boettcher, et al (Eds) Encyclopedia of Distance and Online Learning, 2nd edn, pp. 1900-1906. Hershey, PA: Information Science Reference.

Lowenthal, P.R. (2010) The Evolution and Influence of Social Presence Theory on Online Learning, in T.T. Kidd (Ed), Online Education and Adult Learning: new frontiers for teaching practices, pp. 124-134. Hershey, PA: IGI Global.

Management Class (2014) Group Behavior. http: / / managementclass.co.uk/public_html/courseware/leadership/people_and_org/grp8.htm

Picciano, A.G. (2002) Beyond Student Perceptions: issues of interaction, presence, and performance in an online course, Journal of Asynchronous Learning Networks, 6(1), 21-40.

Richardson, J.C. \& Swan, K. (2003) Examining Social Presence in Online Courses in Relation to Students' Perceived Learning and Satisfaction, Journal of Asynchronous Learning Networks, 7(1), 68-88.

Rourke, L. \& Anderson, T. (2002) Exploring Social Communication in Asynchronous, Text-based Computer Conferencing, Journal of Interactive Learning Research, 13(3), 259-275.

Rourke, L., Anderson, T., Garrison, D.R. \& Archer, W. (1999) Assessing Social Presence in Asynchronous Text-based Computer Conferencing, Journal of Distance Education, 14(2), 50-71.

Rourke, L. \& Kanuka, H. (2009) Learning in Communities of Inquiry: a review of the literature, Journal of Distance Education, 23(1), 19-48.

Shea, P. \& Bidjerano, T. (2009) Community of Inquiry as a Theoretical Framework to Foster 'Epistemic Engagement' and 'Cognitive Presence' in Online Education, Computers \& Education, 52(3), 543-553. http: / / dx.doi.org/10.1016/j.compedu.2008.10.007

Shea, P. \& Bidjerano, T. (2010) Learning Presence: towards a theory of self-efficacy, self-regulation, and the development of communities of inquiry in online and blended learning environments, Computers \& Education, 55(1), 1721-1731. http:// dx.doi.org/10.1016/j.compedu.2010.07.017

Shea, P. \& Bidjerano, T. (2012) Learning Presence as a Moderator in the Community of Inquiry Model, Computers \& Education, 59(2), 316-326. http:/ / dx.doi.org/10.1016/j.compedu.2012.01.011

Shea, P., Hayes, S., Smith, S.U., et al (2012) Learning Presence: additional research on a new conceptual element within the community of inquiry framework, The Internet and Higher Education, 15(2), 89-95. http:/ / dx.doi.org/10.1016/j.iheduc.2011.08.002

Shen, K.N., Khalifa, M. \& Yu, A.Y. (2006) Supporting Social Interaction in Virtual Communities: role of social presence. Paper presented at the 12th Americas conference on information systems, 4-6 August, Acapulco, Mexico.

Shin, N. (2002) Beyond Interaction: the relational construct of 'transactional presence', Open Learning, 17(2), 121-137. http: / / dx.doi.org/10.1080/02680510220146887

Short, J., Williams, E. \& Christie, B. (1976) The Social Psychology of Telecommunications. London: John Wiley \& Sons.

Somekh, B. (Ed.) (2007) Learning for the Twenty-First Century: what really matters? Special Issue, Education and Information Technologies, 10(3).

Stacey, E. (2002) Social Presence Online: networking learners at a distance, Education and Information Technologies, 7(4), 287-294. http:/ / dx.doi.org/10.1023/ A:1020901202588

Swan, K. (2002) Building Communities in Online Courses: the importance of interaction, Education, Communication and Information, 2(1), 23-49. http: / / dx.doi.org/10.1080/1463631022000005016

$\mathrm{Tu}, \mathrm{C.H.}$ (2000) On-line Learning Migration: from social learning theory to social presence theory in a CMC environment, Journal of Network and Computer Applications, 23(1), 27-37.

http: / / dx.doi.org/10.1006/jnca.1999.0099 
Tu, C.H. (2002) The Measurement of Social Presence in an Online Environment, International Journal of ELearning, 1(2), 34-46. http:/ / dx.doi.org/10.1207/S15389286AJDE1603_2

Tu, C.H. \& McIsaac, M. (2002) An Examination of Social Presence to Increase Interaction in Online Classes, American Journal of Distance Education, 16(3), 131-150.

Tuckman, B.W. (1965) Developmental Sequence in Small Groups, Psychological Bulletin, 63(6), 384-399. http: / / dx.doi.org/10.1037/h0022100

Tuckman, B.W. \& Jensen, M.A. (1977) Stages of Small Group Development Revisited, Group and Organizational Studies, 2, 419-427. http: / / dx.doi.org/10.1177/105960117700200404

Vanden Abeele, M., Roe, K. \& Pandelaere, M. (2007) Construct Validation of the Concepts Social Presence, Emotional Presence and Connectedness and an Application of Zajonc's Social Facilitation Theory to Social Presence Research. Paper presented at the 10th annual international workshop on Presence (PRESENCE 2007), 25-27 October, Barcelona, Spain.

Walther, J.B. (1992) Interpersonal Effects in Computer-Mediated Interaction: a relational perspective, Communication Research, 19(1), 52-90. http:/ / dx.doi.org/10.1177/009365092019001003

Walther, J.B. (1993) Impression Development in Computer-Mediated Interaction, Western Journal of Communication, 57, 381-398. http:/ / dx.doi.org/10.1080/10570319309374463

Ward, L.W. (2005) Putting Policy into Practice: pedagogical reform through ICT. PhD dissertation, University of Auckland, New Zealand.

Xin, C. (2012) A Critique of the Community of Inquiry Framework, Journal of Distance Education, 26(1). http:/ / www.jofde.ca/index.php/jde/article/view/755/1333

Yang, X., Li., Y., Tan, C.-H. \& Teo, H.-H. (2007) Students' Participation in an Online Discussion Forum: why is computer-mediated interaction attractive? Information \& Management, 44(5), 456-466. http: / / dx.doi.org/10.1016/j.im.2007.04.003

Zajonc, R.B. (1965) Social Facilitation, Science, 149, 269-274. http:/ / dx.doi.org/10.1126/science.149.3681.269

KAREL KREIJNS is an associate professor at the Scientific Centre for Teacher Research of the Open University of the Netherlands. His current research interests are teachers' usage of ICT, the effects of leadership on teachers' professionalization, and the application of social presence and affordance theory in online learning networks/computer-supported collaborative learning/ community of Inquiry. Correspondence: karel.kreijns@ou.nl

FREDERIK VAN ACKER is a researcher in the School of Psychology, Open University of the Netherlands.

MARJAN VERMEULEN is a part-time associate professor at the Teacher University of the Open University of the Netherlands. She is also a knowledge manager at KPC Holding, an institute that offers advisory and research services to organizations in the field of education. Her research interest is in leadership, collective learning, and motivation theory.

HANS VAN BUUREN is an associate professor at the School of Psychology of the Open University of the Netherlands. He is interested in statistics and research methods in educational research. 